\title{
IMPACT ANALYSIS OF THE CAPABILITY ON STRATEGY VIA OTHELLO GAME
}

Jeremy Albert Novaryan, T. Brenda Ch.

Department of Information System

Soegijapranata Catholic University, Semarang, Indonesia sii_jere@ymail.com 
Abstract - Othello is a game that is already antiquated, but the game is still played by many people. Othello game is played by 2 people. If you want to win over the opponent, you must have a good strategy so that all the pieces on the board into the color of the chip.

Each player would continue to seek a new strategy to make the pieces multiply. Under these conditions, will result in job terstimulasinya brain to strategize. This of course has an impact on the development of creativity in the organization's strategy.

This study was conducted to prove that the game Othello is able to train its player in developing strategies. The results showed that in the Othello game, players are able to train level strategy if he plays continuously. Automatically, playing the game of Othello can stimulate the brain so as to improve the ability to strategize.

\section{Keyword-Strategic, thinking, critical thinking, tactic}

\section{INTRODUCTION}

Othello is a very familiar game for game lovers. This game has already existed since 1945. However, nowadays, Othello games are judged to be too old for some people.

Even though people rate Othello game as an old one, this game is enthused by all statuses in society. This game is played by children, teenagers, and also adults. Because there are many people still interested in this game, this game can exist though there are many other new games.

Nowadays, most people know that Othello is just to make people happy. This game actually has unique superiority and is very useful. This game can train strategy skill of someone to decide the way to act.

\section{THEORETICAL BASIS}

Othello is a game that uses board having $8 \times 8$ square inside it. This game is played by two people by using one board.
The history of game Othello began in 1945, after Atomic bomb was fallen in Hiroshima and Nagasaki on September 1945. Hasegawa Goro, a first grade secondary school accepted the lesson with sit down in the land. Mito also becomes a bomb target until castle and another history building was washed up by fire. In that situation, this game was created. The first rule is if the first player's stone is flanked by the second player's stone, consequently the first player's stone becomes the second player's.

Basically, there are only two color types of chip in Othello game. They are white and black as shown in Figure 1.

The purpose of this game is to get one's opponent's chips many as possible, or to take away the opponent's chips from the game board. A player who has more chips becomes the winner in this game. For the own valuate was explained that is count the amount of all color chip if the game board is full of chip or the opponent cannot do a movement because of there is no chip that can not to jump like Figure 2.

The way to play this game is easy. For example say, the first player uses black chip and the second player uses white chip. For the first turn, the player who has black chip put the black chip on $\mathrm{C} 4$ which jumps through white chip D4 like in Figure 3.

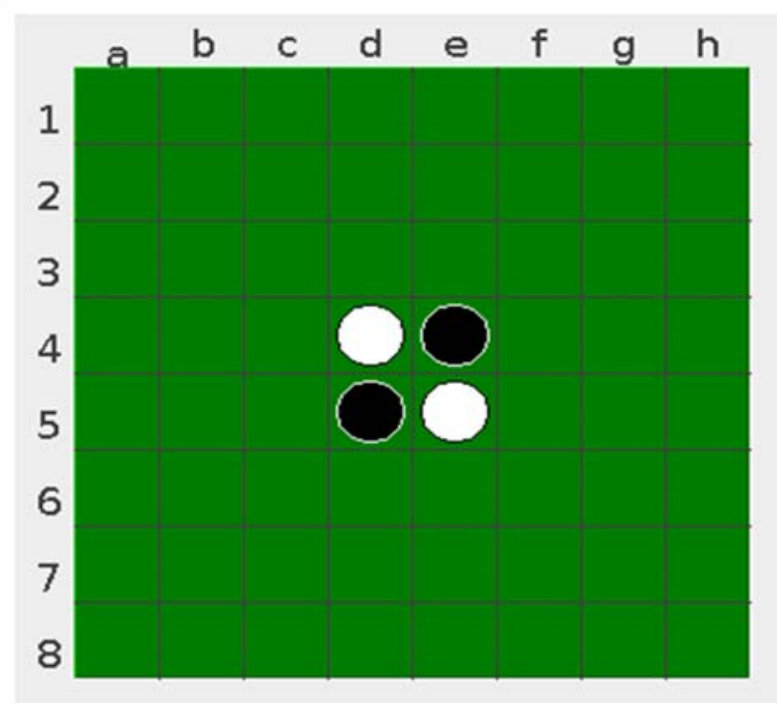

Figure 1 Othello Board 


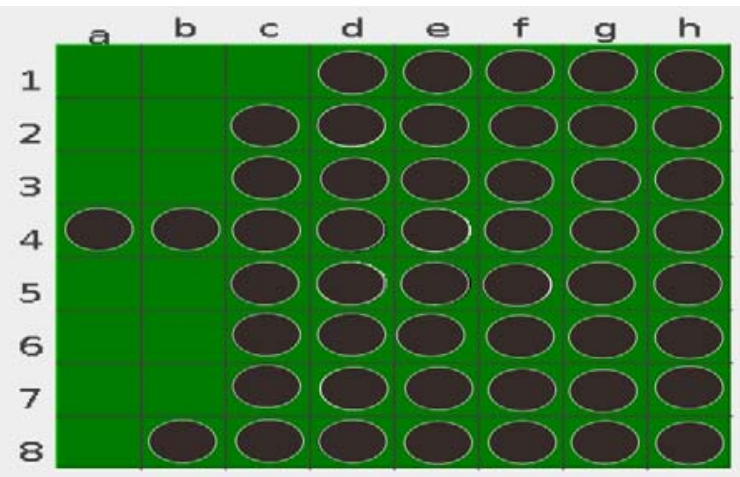

Figure 2 End Game Othello with chip enemies fight out

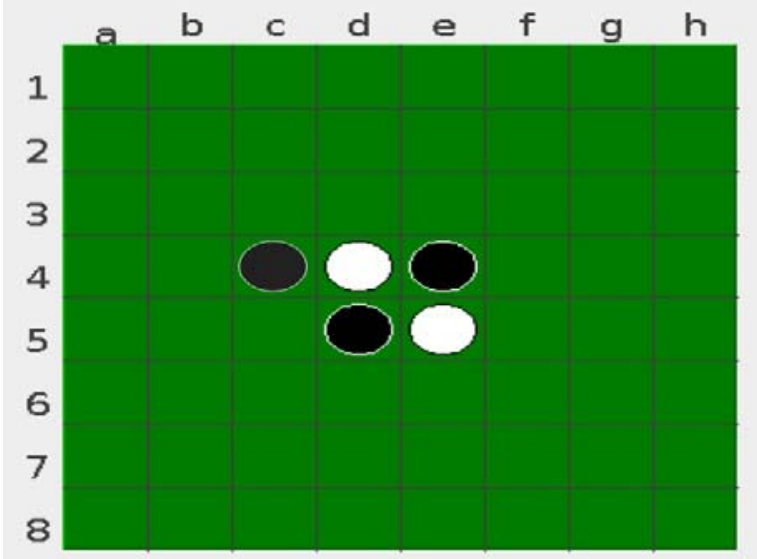

Figure 3. Black chip C4

Automatically, the white chip located in D4 will become black chip like in the Figure 4 .

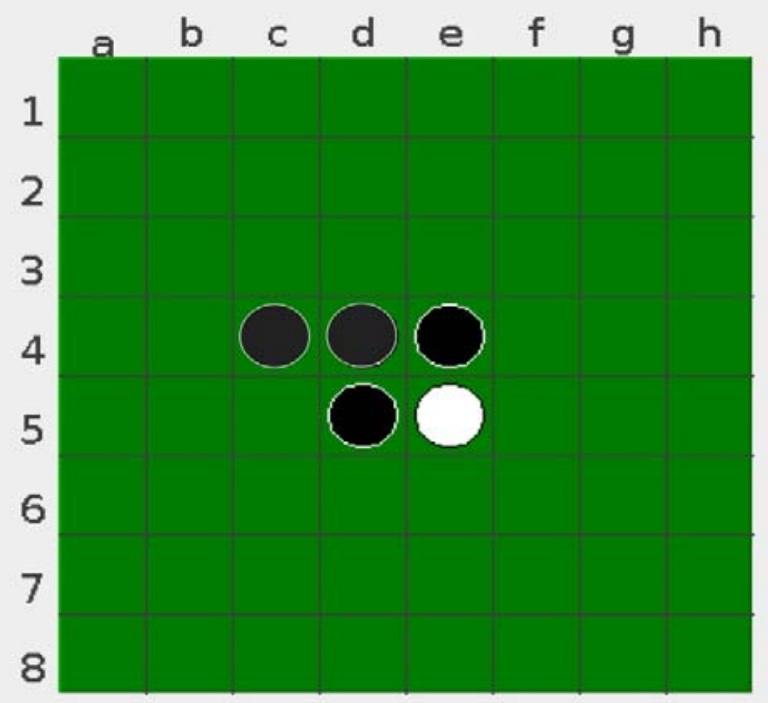

Figure 4 White chip D4 becomes black one
According to the journal "An Analysis of Heuristics in Othello" written by Paul G. Allen Center. In his article, "An Analysis of Heuristics in Othello", Paul G.Allen says that Othello game is Artificial Intelligent game that is played by two players. This game is also designed in order to be played in computer. If in this game the player capable to do good strategy, it can increase skill someone to decide the precious strategy to win the competition. Quote "Improved game play in Othello can result from improvements in the search strategy used" explain that playing Othello game can increase ability to arrange strategy that will be used.

This game needs precious/mature strategy. It cannot separate from the way to play Othello that entails the player to arrange the strategy with many supporting formula to get more chips from the opponent. This game is also meant for multi-players which consequently bears its own difficulties. Since the players have their own strategy to beat their opponent, players should think critically. If their previous strategy fails, they can prepare another new strategy to win the game.

\section{RESEARCH METHODOLOGY}

To prove that Othello game is useful to train strategy ability development of the players, the writer did a research on some people. The writer does this research to 10 Othello game players. Each player should do five competitions with other five players. In every competition, they must do five rounds.

\section{III.I Research}

Table 3.1.1 The research of Game Othello

\begin{tabular}{|c|c|c|c|c|c|c|c|c|c|c|}
\hline $4,5 / 2 / 3$ & A & B & C & $D$ & $\mathrm{E}$ & $\mathrm{F}$ & $G$ & H & I & J \\
\hline $\mathrm{A}$ & 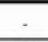 & $(2,3)$ & $(4,1)$ & $(1,4)$ & 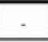 & $(2,3)$ & - &. & $(3,2)$ & - \\
\hline B & $(3,2)$ & $\cdot$ & $(3,2)$ & . &. & $\cdot$ & $\cdot$ & $(2,3)$ & $(4,1)$ & $(3,2)$ \\
\hline C & $(1,4)$ & $(2,3)$ &. & $(2,3)$ &. & $(2,3)$ & & $(2,3)$ &. & $\cdot$ \\
\hline D & $(4,1)$ &. & $(3,2)$ &. & $(5,0)$ &. & $(3,2)$ & $(4,1)$ & . &. \\
\hline E & . & . &. & $(0,5)$ &. & $(2,3)$ & $(1,4)$ & $(3,2)$ &. & $(3,2)$ \\
\hline $\mathrm{F}$ & $(3,2)$ &. & $(3,2)$ & . & $(3,2)$ &. & $(2,3)$ &. & . & $(2,3)$ \\
\hline$G$ &. &. &. & $(2,3)$ & $(4,1)$ & $(3,2)$ & . & & $(3,2)$ & $(1,4)$ \\
\hline H &. & $(3,2)$ & (3.2) & $(1,4)$ & (2.3) &. &. &. & $(2,3)$ &. \\
\hline I & (23) & $(1,4)$ &. & . &. &. & (2.3) & $(3,2)$ & . & $(3.2)$ \\
\hline J &. & (2.3) &. & . & (2.3) & $(3,2)$ & $(4,1)$ &. & (2,3) & . \\
\hline
\end{tabular}


control their strategy quite well.

Source: The results of the data processing itself, 2014
Explanation:
A: Raynaldo
B: Jaslyn
C: Vivie
D: Lukas
E: Alex
F: Muhammad
G: Rini
H: Putri
I: Daniel
$\mathrm{J}$ : Albet

\section{RESULT AND dISCUSSION}

Based on the above table, 10 players have done as much as 5 times a game with other players. Player A gets the wins with a score of 2-3 at the time of the match against player $B$. Player B also got a lot of wins as many as 4-1 against player I. In contrast, the $\mathrm{C}$ players actually got a major defeat in five matches that have been done. Player $\mathrm{D}$ is able to win all the matches with a convincing score. Players E, $\mathrm{H}$, $\mathrm{I}$, J also got the same score with player A, that is, 2-3. Players F and $\mathrm{G}$ achieved a slim score of five games, that is, 3-2.

Based on interviews with all players who have competed. After the first match, most players still have difficulties to strategize to get more pieces. Having finished second competition, players from mimicking the enemy strategy and combine with their strategy - each player. After the third match, the players began to find their own game patterns to find more pieces to get the victory. After the fourth and the fifth games, most players are able to

\section{CONCLUSIONS}

This research is still relatively simple because it only examined 10 players. Each player only did 5 (five) games and each game is done in five (5) innings. In addition, the writer also still used manual research of others. That is, that the author did a little interview after the game the players do. However, this study proves that the play Othello, the ability of the strategy can be developed to do the race strategy in dealing with the opposite problem occurs.

Hope for the future is the agency / group that will conduct research on Othello game that can be used to train a person to develop a strategy someone who played it. Hopefully, with the development of strategies through game play Othello, someone will be able to use these abilities daam solve problems in everyday life, for example by developing a strategy for managing the economy.

\section{Reference}

[1] Bowo Prasetyo. Apa itu Othello?(Online). http://genethello.blogspot.com/2011/06/apa-itu -othello.html, accessed on 22-10-2013

[2] Asakura Kyriel. Othello(Online). http://asakurakyriel.blogspot.com/2011/03/othe llo.html, accessed on 19-11-2013

[3]Chie. Tujuan Permainan dan Scoring (Online).

http://reversi-othello.blogspot.com/2011/09/tuj uan-permainan-dan-scoring.html, accessed on $25-11-2013$ 